\title{
Case Report \\ Familial Pemphigus Vulgaris Occured in a Father and Son as the First Confirmed Cases
}

\author{
Ali Haydar Eskiocak, Birgul Ozkesici, and Soner Uzun \\ Department of Dermatology and Venereology, Akdeniz University School of Medicine, 07059 Antalya, Turkey \\ Correspondence should be addressed to Ali Haydar Eskiocak; aliheskiocak@gmail.com
}

Received 26 December 2015; Revised 9 April 2016; Accepted 15 May 2016

Academic Editor: Alireza Firooz

Copyright ( $) 2016$ Ali Haydar Eskiocak et al. This is an open access article distributed under the Creative Commons Attribution License, which permits unrestricted use, distribution, and reproduction in any medium, provided the original work is properly cited.

\begin{abstract}
Pemphigus vulgaris (PV) is a chronic autoimmune bullous disease of the skin and mucous membranes. Although there is some evidence pointing towards a genetic predisposition by some human leukocyte antigen (HLA) genes, familial occurrence of PV is very rare. Most of the familial PV cases so far reported have been in mother and daughter and in siblings. PV in father and son, as presented here, has not been reported in the literature before, except an unconfirmed report. The diagnosis of PV was established by histologic, cytologic studies and enzyme linked immunosorbent assay (ELISA) in Case 1 and by ELISA and BIOCHIP indirect immunofluorescence test in Case 2. The son was responsive to moderate doses of methylprednisolone, with the treatment continuing with tapered doses. The father was in a subclinic condition; consequently, only close follow-up was recommended. HLA typing studies revealed identical HLA alleles of HLA-DR4 (DRB1 $\left.{ }^{*} 04\right)$ and HLA-DQB1* 03 in both of our cases; this had been found to be associated with PV in prior studies. Familial occurrences of PV and related HLA genes indicate the importance of genetic predisposition. The first occurrence of confirmed familial PV in father and son is reported here.
\end{abstract}

\section{Introduction}

Pemphigus vulgaris (PV) is a life-threatening chronic autoimmune disease, associated with loss of adhesion between keratinocytes and characterised by mucosal and cutaneous blisters and erosions. It is caused by autoantibodies that bind to the keratinocyte surface antigens desmogleins (Dsg) 1 and 3. However, genetic predisposition and exogenous triggering factors play an important role in etiology [1]. Familial pemphigus is very rare and only a few cases have been published. To the best of our knowledge, there are no confirmed familial PV cases in father-son relationships in the literature thus far. Here, we present cases of the son PV patient followed up by our clinic till now and father PV patient diagnosed previously.

\section{Material and Methods}

A 31-year-old man, who was the son of Case 2 described below, was referred to our outpatient clinic in March, 2015, due to having oral lesions for the preceding 8 months. A biopsy, taken from the lesions by another center where the patient had been referred to at the beginning of his complaints, shows intraepidermal dissociation and negative direct immunofluorescence examination. There was no feature in his medical background. Physical examination revealed extensive erosions on the buccal mucosa, soft palate, and oropharynx, with extremely limited epithelized erosions on his chin. The Nikolsky sign was positive and Tzanck smear test showed acantholytic cells in the oral lesions. Anti-Dsg 1 and Anti-Dsg 3 antibodies were found to be positive in titers of 20 and $87 \mathrm{IU} / \mathrm{mL}$ in enzyme linked immunosorbent assay (ELISA), respectively (EUROIMMUN, Lübeck, Germany). The BIOCHIP indirect immunofluorescence (IIF) test (EUROIMMUN, Lübeck, Germany) was negative. A diagnosis of mucocutaneous PV was established. Human leukocyte antigen (HLA) typing by polymerase chain reactionsequence specific primers (PCR-SSP) method showed the following: class 1: $\mathrm{A} 1, \mathrm{~A} 3, \mathrm{~B} 7, \mathrm{~B} 35, \mathrm{C} 7$, and $\mathrm{C} 15$; class 2: $\mathrm{DRB}^{*}{ }^{*} 04, \mathrm{DRB} 1{ }^{*} 11$, and DQB1 ${ }^{*} 03$. Forty-eight $\mathrm{mg}$ per day oral methylprednisolone therapy was initiated. The patient achieved remission and the therapy was continued with tapered doses. 
TABLE 1: Familial pemphigus vulgaris cases found in the PubMed database. PE: pemphigus erythematosus, PF: pemphigus foliaceus, and PV: pemphigus vulgaris.

\begin{tabular}{lcccc}
\hline Author & Date & Disease & Patients \\
\hline Yamamoto et al. [8] & 2011 & PV and PF & Daughter with PF and mother with PV; one sister with PF and another sister with PV \\
Bordel-Gómez et al. [13] & 2006 & PV & Three brothers/two brothers/a brother and a sister \\
Kavak et al. [3] & 2005 & PV & A brother and a sister \\
Gokdemir et al. [4] & 2004 & PV & A brother and a sister \\
Stavropoulos et al. [14] & 2001 & PV & Two sisters \\
Starzycki et al. [2] & 1998 & PV & A mother and a daughter \\
Revenga-Arranz et al. [15] & 1996 & PV & Two brothers \\
Reohr et al. [16] & 1992 & PV & Two siblings \\
Feinstein et al. [17] & 1991 & Pemphigus & Two sisters \\
Katzenelson Weissman et al. [18] & 1990 & PV & A mother and a son \\
Alijotas et al. [19] & 1990 & PV & Two siblings \\
Brenner et al. [20] & 1990 & PV and PE & Two sisters \\
Laskaris et al. [21] & 1989 & PV & PV & A sister and a brother/a daughter, a son, and their mother \\
Graham-Brown and Lister [22] & 1987 & PVother and a daughter \\
Spinowitz et al. [23] & 1986 & PV & Sisters \\
Brenner et al. [24] & 1985 & PV & An uncle and a niece \\
Ahmed and Sofen [25] & 1982 & PV & PV & PV \\
Sheklakov and Mashkilleison [26] 1965 & 1949 & PV & A mother and a daughter/a brother and a sister \\
Miller and Frank [27] & 190 A mother and a daughter
\end{tabular}

A 54-year-old man, the father of Case 1 described above, was referred to our outpatient clinic with recurrent oral lesions after his son had been diagnosed with PV. We learned that his oral erosions began in 1995 and they were followed by cutaneous blisters after a period of 2 months. In accordance with the histopathological examination performed in the medical center that he was referred to first in 1995, he was diagnosed as PV. Oral prednisolone $80 \mathrm{mg} /$ daily was initiated and the dose was reduced after about 2 months. After the treatment had continued for about 5 years with tapered doses, the lesions were completely cleared and he was in remission for about 15 years. New transient lesions have been developing, especially on his palate after consuming tough foods, and then disappearing spontaneously within 3 or 4 days, for the last 2 years. He was operated on for inguinal hernia and recovered from brucellosis 10 and 8 years ago, respectively.

There was neither erosion nor blister, and the Nikolsky sign was negative in dermatological examination at the time he was referred to our clinic. General physical examination was also normal. Anti-Dsg 3 antibodies were positive in titer of $70 \mathrm{IU} / \mathrm{mL}$, while anti-dsg 1 antibody was negative with ELISA. Additionally, BIOCHIP IIF was performed and showed the following results: intercellular intraepidermal staining with IgG in monkey oesophagus substrate and antidsg 3 antibody deposits in dsg 3 transfected human embryonic kidney cells were detected. HLA typing by PCR-SSP method showed the following: class 1: A2, A3, B35, C4, and $\mathrm{C} 15$; class 2: $\mathrm{DRB} 1^{*} 04$ and $\mathrm{DQB1}{ }^{*} 03$. The patient's previous diagnosis of PV was confirmed according to the medical history and the positive ELISA and IIF tests. He was informed and close follow-up was recommended, with no requirement of treatment.

\section{Discussion}

Although there is some evidence concerning exogenous triggering factors and genetic predisposition in pemphigus, definite etiology has not been clarified yet [2]. Familial PV is very rare: there are about 45 cases found in the literature so far (Table 1). Two Turkish siblings with simultaneous onset of PV and two Armenian origin siblings with unusual localized variant PV are the only cases reported in Turkey $[3,4]$. Most of the familial PV patients reported are in mother and daughter, mother and son, and siblings. To the best of our knowledge, there is no documented familial PV case in father and son except an unconfirmed case reported in 1940 [5]. Immunofluorescence diagnostic techniques were not available at the time of that report; therefore, definite diagnosis of PV could not be established. In this context, our cases hold the distinction of being the first confirmed father and son familial PV. The occurrence of PV in parents and children indicates the important role of inheritance [2]. It is suggested that HLA genes are related to the disease and pemphigus is also thought to be associated with class II alleles such as DR4 and DR6 after serological typing studies [6]. The HLA-DR4 allele is most strongly associated with Jewish PV patients (in almost $90 \%$ of cases), especially in Ashkenazi Jews, and $60 \%$ of Japanese patients [7, 8]. An increased frequency of HLADR4, DQ8, DR6, and DQ5 has also been found within the non-Jewish population [4]. Furthermore, HLA-DQ alleles, such as HLA-DQB1*0302 and DQB1*0503, are also found to be associated with pemphigus in different ethnic groups with restriction fragment length polymorphism method [8]. Because PV may be associated with some HLA alleles, we investigated the HLA types of our cases. Both of our 
cases presented identical HLA-DR4 (DRB1 $\left.{ }^{*} 04\right)$ and HLADQB1* 03 alleles, consistent with the mentioned reports. It has been demonstrated that dsg 3 epitopes, recognized by autoreactive $\mathrm{T}$ helper cells, are carried by the aforementioned PV-associated HLA alleles [9]. However, the same antigenic epitopes have been also demonstrated with healthy carrier individuals [9]. Furthermore, the same HLA alleles were demonstrated in both the patients and their healthy firstdegree relatives in 2 studies [3]. These findings imply that the existence of the related HLA genes alone is not sufficient for development of pemphigus $[2,8]$. The pemphigus autoantibodies were demonstrated in the sera of the first-degree healthy relatives of patients with pemphigus in some previous studies, which can be put forward as evidence of the genetic basis of the disease. An investigative study with 29 patients with pemphigus and 68 first-degree healthy relatives showed the titers of $1 / 20$ and above of circulating antibodies in sera as statistically significant between healthy relatives and healthy controls in rat oesophagus substrates [10]. Another study with the same design similarly also showed higher IIF test positivity in healthy relatives than healthy controls [11]. Circulating anti-dsg antibodies were also demonstrated with ELISA in $\% 19,4$ healthy relatives of pemphigus patients in a study [12]. According to recent findings, related HLA genes and circulating autoantibodies seem not to be sufficient for the disease to develop in first-degree healthy relatives of patients with pemphigus. There may, therefore, be some unknown additional factors for occurrence of clinic manifestations.

There are some points that could be considered as limitations in our observation. The direct immunofluorescence test was negative in Case 1 and could not be performed in Case 2 because of the lack of active pemphigus lesion. However, there was almost no doubt with the diagnosis of PV of the patients, taking into account all of the medical history, clinical, cytological, and histopathological findings, and immunofluorescence studies of the patients. Also, it would be very appropriate to follow up with a study of the HLA types of all first-degree relatives of the cases to demonstrate the HLA allele profile of the family; unfortunately, that was not possible because of the patients' condition.

\section{Conclusion}

First confirmed familial PV cases in father and son are presented here. Although the occurrence of PV in first-degree relatives indicates the importance of genetic predisposition, it is clear that further studies are required to clarify the definite aetiopathogenesis.

\section{Competing Interests}

The authors declare that they have no competing interests.

\section{References}

[1] S. Uzun, Pemfigus, Dermatoloji, Edited by Y. Tüzün, S. Serdaroğlu, V. L. Aksungur, M. A. Gürer, and O. Oğuz. 3. Baskı, cilt 1 , sf $807-832$.
[2] Z. Starzycki, T. P. Chorzelski, and S. Jablonska, "Familial pemphigus vulgaris in mother and daughter," International Journal of Dermatology, vol. 37, no. 3, pp. 211-214, 1998.

[3] A. Kavak, I. Aydoğan, and S. Gönen, "Simultaneous onset of pemphigus vulgaris in two Turkish siblings," Journal of Dermatology, vol. 32, no. 3, pp. 186-188, 2005.

[4] G. Gokdemir, S. Gonen, I. Kwanç-Altunay, and A. Köşlü, "Familial pemphigus vulgaris: two siblings with unusual localized variant," International Journal of Dermatology, vol. 45, no. 2, pp. 170-172, 2006.

[5] S. Sigmund and M. D. Greenbaum, "Cases of familial and of conjugal pemphigus vulgaris. Use of transfusions of blood from cured patients," Archives of Dermatology and Syphilology, vol. 41, no. 6, pp. 1073-1075, 1940.

[6] A. R. Ahmed, A. Mohimen, E. J. Yunis et al., "Linkage of pemphigus vulgaris antibody to the major histocompatibility complex in healthy relatives of patients," The Journal of Experimental Medicine, vol. 177, no. 2, pp. 419-424, 1993.

[7] A. R. Ahmed, E. J. Yunis, K. Khatri et al., "Major histocompatibility complex haplotype studies in Ashkenazi Jewish patients with Pemphigus vulgaris," Proceedings of the National Academy of Sciences of the United States of America, vol. 87, no. 19, pp. 7658-7662, 1990.

[8] T. Yamamoto, K. Ikeda, S. Sasaoka et al., "Human leukocyte antigen genotypes and antibody profiles associated with familial pemphigus in Japanese," The Journal of Dermatology, vol. 38, no. 7, pp. 711-716, 2011.

[9] M. Hertl, R. Eming, and C. Veldman, "T cell control in autoimmune bullous skin disorders," The Journal of Clinical Investigation, vol. 116, no. 5, pp. 1159-1166, 2006.

[10] S. Günaştı and S. Uzun, "Pemfiguslu hastaların sağlıklı birinci derece akrabalarında pemfigus otoantikorlarının sıklığının araştırılması," Turkiye Klinikleri Journal of Medical Sciences, vol. 30, no. 2, pp. 571-576, 2010.

[11] M. Kavala, Ö. E. Kocatürk, C. Demirkesen, B. Can, I. Zindanci, and Z. Türkoglu, "Detection of pemphigus autoantibodies in healthy relatives of Turkish patients with pemphigus," Indian Journal of Dermatology, Venereology and Leprology, vol. 73, no. 4, pp. 240-242, 2007.

[12] J. D. Torzecka, K. Woźniak, C. Kowalewski et al., "Circulating pemphigus autoantibodies in healthy relatives of pemphigus patients: coincidental phenomenon with a risk of disease development?" Archives of Dermatological Research, vol. 299, no. 5-6, pp. 239-243, 2007.

[13] M. T. Bordel-Gómez, J. Sánchez-Estella, M. Yuste-Chaves, J. C. Santos-Durán, and M. T. A. Pablo, "Familial pemphigus vulgaris: immunogenetic study of HLA class II antigens," Actas Dermo-Sifiliograficas, vol. 97, no. 8, pp. 509-513, 2006.

[14] P. G. Stavropoulos, G. Zarafonitis, A. Petridis, T. Hashimoto, K. E. Harman, and M. M. Black, "Pemphigus vulgaris in two sisters," Acta Dermato-Venereologica, vol. 81, no. 2, p. 149, 2001.

[15] F. Revenga-Arranz, J. Martínez-Lasso, and F. VanaclochaSebastián, "Pemphigus vulgaris in two MHC-Haploidentical brothers," Dermatology, vol. 193, no. 1, pp. 71-72, 1996.

[16] P. B. Reohr, A. Mangklabruks, A. M. Janiga, L. J. DeGroot, Y. Benjasuratwong, and K. Soltani, "Pemphigus vulgaris in siblings: HLA-DR4 and HLA-DQw3 and susceptibility to pemphigus," Journal of the American Academy of Dermatology, vol. 27, no. 2, pp. 189-193, 1992.

[17] A. Feinstein, S. Yorav, M. Movshovitz, and M. Schewach-Millet, "Pemphigus in families," International Journal of Dermatology, vol. 30, no. 5, pp. 347-351, 1991. 
[18] V. Katzenelson Weissman, M. David, R. Zamir, J. Mellibovsky, C. Idises, and M. Sandbank, "Familial pemphigus vulgaris," Dermatologica, vol. 181, no. 1, pp. 48-50, 1990.

[19] J. Alijotas, R. Pedragosa, J. Bosch, and M. Vilardell, "Prolonged remission after cyclosporine therapy in pemphigus vulgaris: report of two young siblings," Journal of the American Academy of Dermatology, vol. 23, no. 4, pp. 701-703, 1990.

[20] S. Brenner, E. Hodak, D. Dascalu, R. Lurie, and R. Wolf, "A possible case of drug-induced familial pemphigus," Acta Dermato-Venereologica, vol. 70, no. 4, pp. 357-358, 1990.

[21] G. Laskaris, A. Sklavounou, A. Stavrou, and K. Stavropoulou, "Familial pemphigus vulgaris with oral manifestations affecting two Greek families," Journal of Oral Pathology and Medicine, vol. 18, no. 1, pp. 49-53, 1989.

[22] R. A. C. Graham-Brown and D. M. Lister, "Pemphigus in an Indian mother and daughter," British Journal of Dermatology, vol. 116, no. 2, pp. 253-258, 1987.

[23] A. L. Spinowitz, V. C. Fiedler-Weiss, T. Fu, and L. M. Solomon, "Pemphigus vulgaris in sisters," Journal of the American Academy of Dermatology, vol. 15, no. 1, pp. 115-116, 1986.

[24] S. Brenner, B. Dorfman, and M. Himelfarb, "Familial pemphigus vulgaris," Dermatologica, vol. 171, no. 1, pp. 38-40, 1985.

[25] A. R. Ahmed and H. Sofen, "Familial occurrence of pemphigus vulgaris," Archives of Dermatology, vol. 118, no. 6, pp. 423-424, 1982.

[26] N. D. Sheklakov and A. L. Mashkilleison, "Familial pemphigus vulgaris in mother and daughter," Vestnik Dermatologii $i$ Venerologii, vol. 39, pp. 80-81, 1965.

[27] O. B. Miller and L. J. Frank, "Familial pemphigus vulgaris; report of a case," Archives of Dermatology and Syphilology, vol. 59, no. 4, p. 484, 1949. 


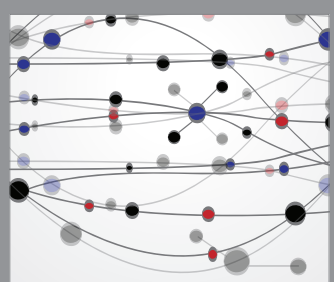

The Scientific World Journal
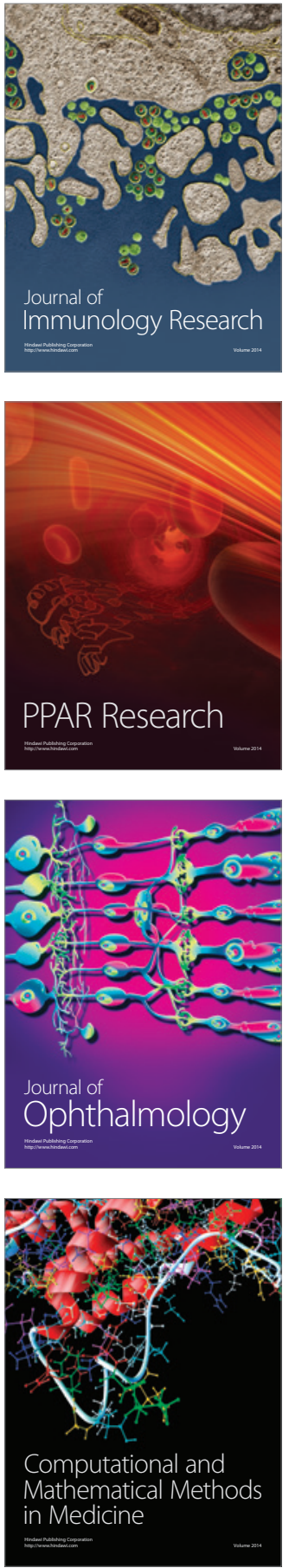

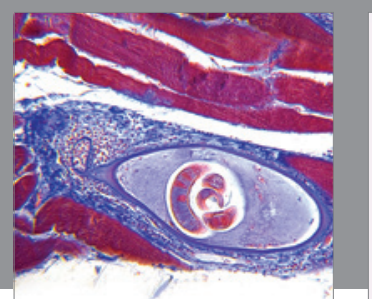

Gastroenterology Research and Practice

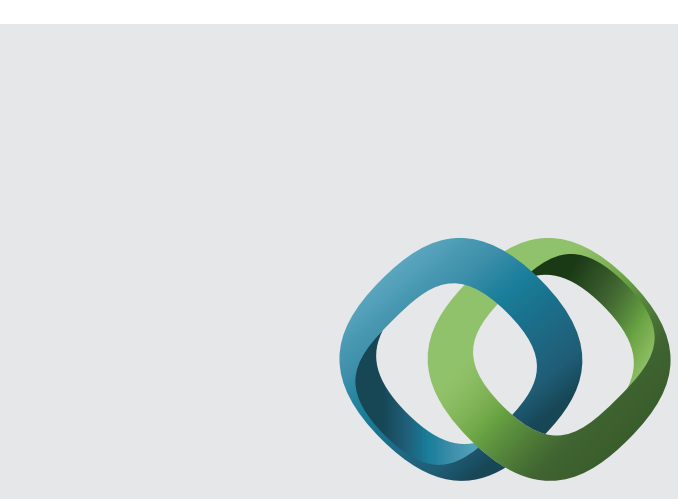

\section{Hindawi}

Submit your manuscripts at

http://www.hindawi.com
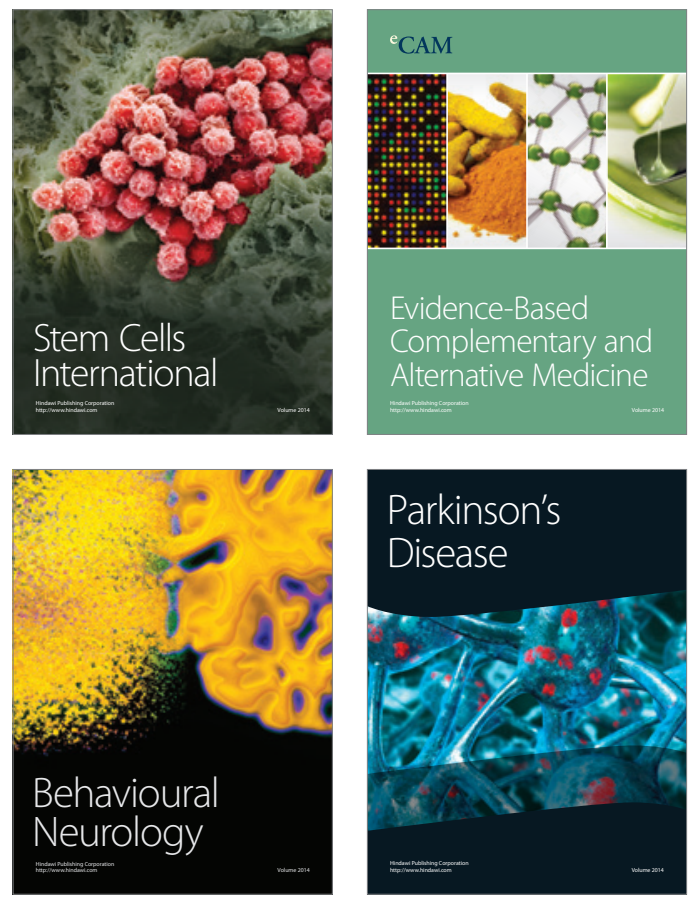
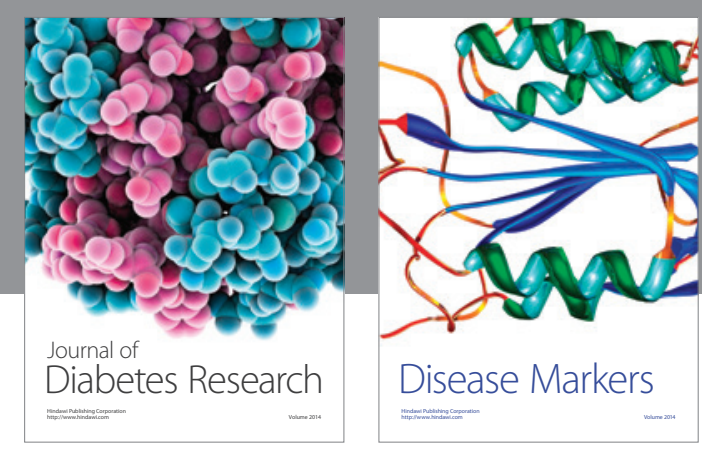

Disease Markers
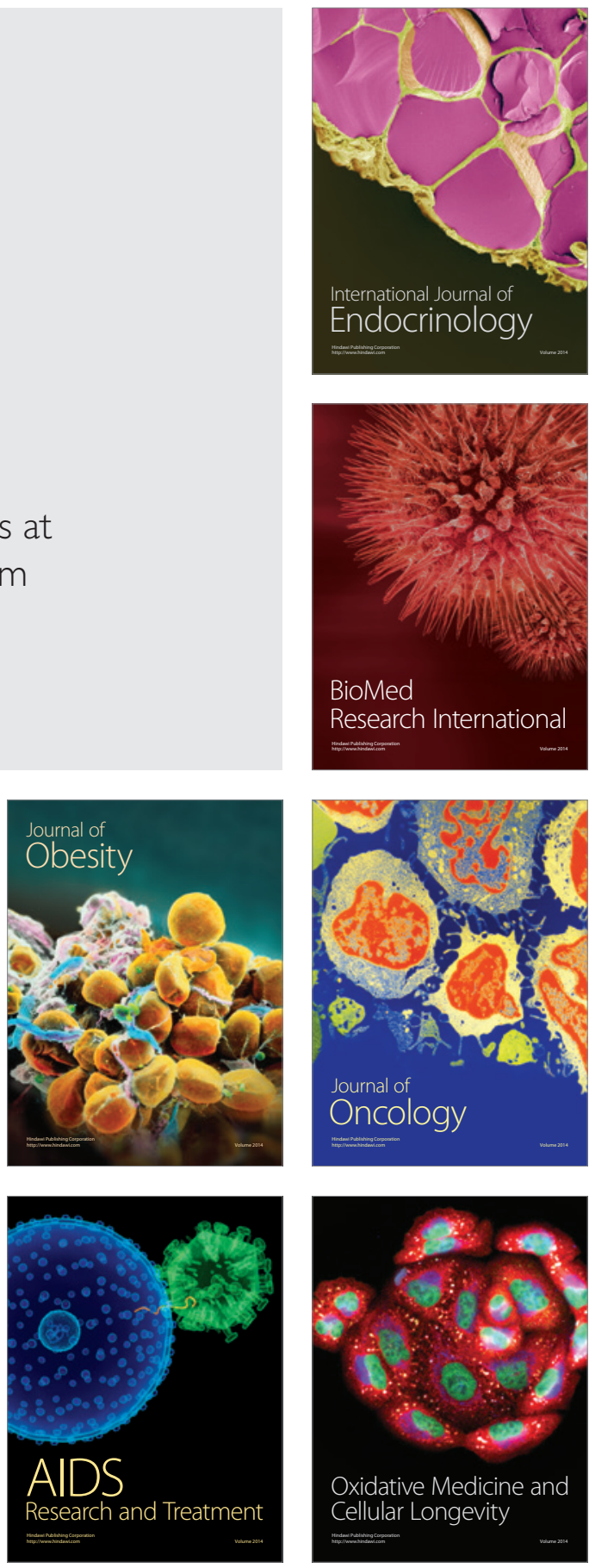